\title{
Supply Function Competition in a Mixed Electric Power Market
}

\author{
Marc Escrihuela-Villar* Carlos Gutiérrez-Hita ${ }^{\dagger \ddagger} \quad$ José Vicente-Pérez ${ }^{\S}$ \\ Manuscript ID JPET-19-01109.R1 \\ Received: October 11, 2019 | Accepted: January 24, 2020
}

\begin{abstract}
In this paper, we present a mixed oligopoly model where electric power generators compete in supply functions in a liberalized market. A former monopolist, the stateowned generator, is assumed to be (partially) privatized. First, we obtain that there is a relationship between privatization and the number of electric power generators concerning the level of consumer surplus and total welfare. Indeed, a fully state-owned generator is socially optimal, lowering private generators' profits and enhancing consumer surplus; i.e., if the degree of privatization decreases, consumer surplus increases compensating the damage imposed on generators' profits. Second, as the number of generators increases, full privatization may provide similar levels of consumer surplus and social welfare than those observed in a mixed oligopoly. Moreover, it is also obtained that price-cost margins increase as marginal cost increases. Overall, our results suggest that the state-owned generator should be privatized when entry barriers are low enough, and competitiveness is enhanced. Otherwise, a state-owned generator may protect consumers, enhancing consumer surplus.
\end{abstract}

Keywords: electric power market; supply function competition; mixed oligopoly.

JEL Classification: D43; H42; L13; L94.

\section{Short running title: SFC in a Mixed Electric Power Market}

Funding Information: Financial support under the projects PGC2018-097965-B-I00 (MCIU/AEI/FEDER, UE), ECO2015-67901-P and ECO2016-77200-P (MINECO/FEDER, UE) is gratefully acknowledged.

*Departament d'Economia Aplicada, Universitat de les Illes Balears, 07122 Palma de Mallorca, Spain. E-mail address: marc.escrihuela@uib.es ORCID: 0000-0002-5119-2415

${ }^{\dagger}$ Departamento de Estudios Económicos y Financieros, and Center of Operations Research (CIO), Universitas Miguel Hernández, 03202 Elche, Spain. E-mail address: cgutierrez@umh.es ORCID: 0000-00033156-1356 (Corresponding author)

${ }^{\ddagger}$ Universidad Antonio de Nebrija, Madrid, Spain.

${ }_{\S}$ Departamento de Matemáticas, Universidad de Alicante, 03071 Alicante, Spain. E-mail address: jose.vicente@ua.es ORCID: 0000-0002-7064-1239 


\section{Introduction}

During the last decade of the XX century, a number of countries began a liberalization process of the electricity system. Traditionally, the electric power generation sector was a stateowned monopoly. As a result of huge demand increases, government budget constraints, and technology improvements, the sector was ready to introduce competition. At the same time, governments decided a total (or partial) privatization of the state-owned power generation monopolist, while a reduced number of private electric power generators entered the market. Thus, it is interesting to study the effects that two distinct policies (liberalization of the market and partial or total privatization of the state-owned power generator) have in the market. ${ }^{1}$ Since liberalization, wholesale electricity markets were mostly organized as bidding markets where electric power generators compete by submitting price-quantity bids in daily interaction. ${ }^{2}$ Although regulatory authorities expect both, competitive price-cost margins and absence of electric fall-outs, wholesale electricity markets were found to have prices well above competitive levels.

In this paper, we investigate the extent to which privatization, the cost structure, and the number of competitors affect market outcomes in a context where electric power generators strategically interact in supply schedules. In fact, such schedules can be seen as a continuum of bids, that is, a supply function. Since the seminal paper by Klemperer and Meyer (1989), the literature in electric power markets organized as bidding systems borrows this model to characterize generators' bidding behaviour. ${ }^{3}$ Moreover, from a technical point of view, the use of supply function schedules to model electric power generation is also advised (see, for instance, Day et al. (2002)). In this strand, a pioneering paper by Green and Newbery (1992) analyzed the British wholesale electricity markets in a context of supply function competition. It is shown that the Nash equilibrium in supply schedules implies a high markup over marginal cost and substantial deadweight losses. Green (1996) introduces in the discussion the effect of the government policies aimed to increase the amount of competition in the electricity spot market in England and Wales. Under linear supply function competition with asymmetric firms, it is found that partial divestiture should lead to a substantial reduction in deadweight losses. In Green (1999), it is also analyzed the impact of long-term contracts in spot electricity prices for the England and Wales market. More recently, in Holmberg and Newbery (2010) and Holmberg et al. (2013), various features of recent developments concerning spot electricity markets, and technical features of supply function competition have been studied. In addition, Newbery and Greve (2017) also emphasize that markup models may explain competitive behaviour in electricity markets and thus, they can also be used as a modeling approach. There are also in the literature some refinements of the supply function model and its comparison with the traditional oligopoly models where the implications to model real markets are presented. For instance, in Vives (2011) supply function competition with random costs is introduced. A Bayesian supply function equilibrium is characterized where supply functions are steeper with a higher correlation among the cost parameters. He shows that as correlation becomes maximally negative, the competitive outcome is obtained, whereas a positive correlation enhances strategic behaviour. Concerning the use of alternative models to characterize oligopoly competition, Delbono and Lambertini (2016) shows that the ranking of firms' profits under the supply function competition and its comparison with Cournot and Bertrand strongly depend on the marginal cost. In particular, they remark that Bertrand-Nash equilibria provide higher profits and lower social welfare than the supply function and Cournot equilibria when the marginal cost is high and, consequently, that the 
choice of the different ways to model market competition should take it into account. In this line, several papers have considered the relationship between competition and the optimal privatization policy using different competition models. More precisely, De Fraja and Delbono (1989) and subsequent literature (see, for instance, Matsumura 1998) showed that in a homogeneous oligopoly, in some cases, a public firm should be privatized and should maximize profits rather than welfare. The intuition is that privatization might increase welfare since with a large number of private firms, the public firm must produce a very high level of output, driving private profits to a very low level. When the possibility of partial privatization is also considered, partial privatization is the optimal policy in the short-run, whereas full nationalization becomes optimal in the long-run with free entry among private firms (see Matsumura and Kanda 2005). Considering a price-setting game with product differentiation, Anderson et al. (1997) show that full nationalization is the best policy in the short-run with an exogenous number of firms while, in the long run, privatization may lead to further entry and become beneficial.

To the best of our knowledge, the study of mixed oligopolies in electric power generation has been neglected in the literature. Electric power generation was traditionally covered by firms under state-ownership. The inefficiency of most of these generators acting as monopolists was the main argument for partial or full privatization in such a way that, in the path towards liberalization, some governments decided that the former state-owned generator were partially or fully privatized whereas in other countries electric power generation remains under public hands.

There is large evidence across the world of state-owned firms competing with private electricity generators. Jamasb and Pollitt (2005) introduced the energy market liberalization process and the long-term objective of a single European energy market. They discussed the emerging issues of market concentration, investments, and security of supply as well as some aspects of the market design and its regulation. They also remark the importance of the transition from state-owned generator firms towards private competition. The evidence in EU country members after two decades of liberalization is mixed. For instance, the Central Electricity Generating Board (CEGB) was the state-owned responsible for generation and transmission in the United Kingdom. The two major generators, National Power and PowerGen, were sold in 1991 . The government retained a $40 \%$ equity position, while the remaining shares were picked up by institutional and foreign investors. The government also sold South of Scotland (currently Scottish Power) and North of Scotland Hydro (currently Scottish Hydro) but retained $100 \%$ of Nuclear Electric. Électricité de France (France), the former state-owned monopolist, remains almost entirely owned by the state. Electric power generation is dominated by nuclear power (accounted for $72.3 \%$ of total production in 2016) which is almost entirely owned by the French government. In the other extreme case, firms as Endesa (Spain), a former state-owned firm, were partially privatized during the last decade of the XX century, reaching $100 \%$ of private equities during the first decade of the XXI century. In Germany, the electricity sector is traditionally characterized by a coexistence of public, private and mixed-economy firms. Sweden shows similarities with the German electricity sector for it is made up from public, mixed-economy as well as private firms and had at no time been neither completely nationalized nor privatized. In Italy, the former state-owned firm ENEL was also fully privatized. Some countries, most notably the US, opted to supply electricity using regulated private monopolies that owned both the generation capacity and the regional transmission networks. In Canada, the electricity sector is dominated by large state-owned integrated firms playing a leading role in the generation, 
transmission, and distribution organized along provincial and territorial lines. Exceptions to this rule are Ontario and Alberta, which have recently created electricity markets in order to increase competition. Results of privatization in less developed countries are also mixed. Some of these countries have favoured public ownership of electric power supply since it is considered part of the infrastructure of the economy and thus, an important ingredient of economic growth. While electricity can be generated using small stand-alone plants, the cost is usually much higher than the marginal cost of grid power. The problem is that the up-front investment costs for an electricity grid are very large. As demand for power may not be sufficient to justify the private investment, the government might undertake this task. For instance, this is the case of the Mexican industry where electric power generation is under the control of the Comisión Federal de Electricidad (CFE), which is a vertically integrated firm controlling most of the generation (75\%), transmission and distribution of electricity in the country. In Brazil, Centrais Elétricas Brasileiras SA, a former state-owned monopolist, is almost entirely owned by the state. In contrast, the gradual privatization process in Argentina has found to increase both access to and quality of service. In Chile, where the electric power sector was fully privatized, Fisher and Serra (2004) find that the sector has improved in installed capacity, generation, energy sold, labour productivity, and profitability of the utility. A complete survey for Latin America countries can be found in Balza et al. (2013).

In this approach, we highlight the role that the state-owned generators play in liberalized wholesale electric power markets. As we pointed out above, during the liberalization process, it was a stylized fact that the former state-owned electric power generator was partially or almost privatized in order to compete with the private generators emerged during the second middle of the XX century. Then, it is interesting to explain how a state-owned generator may modify the competitive behaviour of the private generators. Indeed, we think it is interesting to analyze how the level of privatization affects market results and consequently, welfare. Moreover, the level of marginal cost and the number of generators active in the market may have a different impact on market outcomes as a result of the different levels of privatization. In our model, a state-owned generator competes with private power generators. As a benchmark, we first characterize a market outcome where a stateowned generator and $n \geq 2$ private generators compete in supply schedules. As mentioned above, the literature including supply function competition in mixed oligopolies is scarce. Recently, Yasui and Haraguchi (2018) have presented a supply function duopoly model with a partially privatized public firm and a profit-maximizing firm. They found that the public firm's aggressive behaviour makes the private firm more aggressive in supply function competition and consequently full nationalization is optimal. In Gutiérrez-Hita and VicentePérez (2018) supply function competition with heterogeneous goods in a mixed oligopoly is also analyzed. It is found that social welfare and in particular consumer surplus are affected by the nature of the heterogeneity of goods (substitutes or complements). Another exception is Menezes and Pereira (2017) that investigate the optimal environmental policy in a dynamic setting with R\&D where firms compete in supply schedules. They show that the impact of increased competition on welfare depends on the extent of the market and the nature of preferences and technology.

In the present paper, once the benchmark model is solved, we introduce the discussion of how variations in the degree of privatization, free entry, and the level of marginal costs, affect market outcomes (price and electric power traded), consumer surplus, and social welfare. Overall, it is shown that, in our context of linear supply functions, consumer surplus and 
social welfare are enhanced when free entry is allowed or, alternatively, when the former stateowned monopolist remains under public hands. ${ }^{4}$ Moreover, when cost increases, generators apply higher price-cost margins yielding an increase in market power. Our results suggest that in those countries where electric power generation is provided by a reduced number of firms, the state should control a significant volume of equities of the partially privatized state-owned generator. If the aim of the government is to minimize market intervention, the regulatory body of rules should allow almost free entry in order to enhance competitiveness. As mentioned above, in the nineties, many countries like United States, Chile, and others within the EU (Great Britain, Spain, Germany, etc.) begin to implement reforms aimed to privatize and restructure the electric power industry. Several authors though have found that wholesale prices increased well above marginal cost and that some degree of collusion can be observed in the market. Many involved in electricity restructuring have expressed concern about supplier market power that may raise prices in a deregulated market. ${ }^{5}$ In this line, Hyman (2010) has shown that in the United States and the UK, the old regulated electric industry provided often a reliable service with declining real prices. Even though the old industry had weak incentives to operate efficiently, and that in the present semicompetitive markets the electricity suppliers can perhaps operate more efficiently than before, the consumers do not obtain benefits significantly greater than they would have under the old market structure.

The rest of the paper is organized as follows. Section 2 presents the benchmark model and characterizes the equilibrium. Section 3 analyzes how the level of privatization, free entry, and changes in production costs affect strategic behaviour. Section 4 studies the extent to which free entry makes it unnecessary the presence of a state-owned generator in the market. Section 5 concludes and gives some policy implications. Proofs are relegated to the Appendix.

\section{A mixed market of electric power generation}

In a mixed oligopoly, a (partially) state-owned electric power generator, that we denote by firm 0 , and $n$ private generators compete by offering simultaneously price-quantity auctions in a supply function fashion. ${ }^{6}$ The aggregate supply function provides electric power to meet consumers' demand. Moreover, as price-quantity auctions are performed day-ahead, the final realization of demand is somehow uncertain, in the sense that the amount of electric power that consumers are willing to demand is not known a priori. Thus, it is necessary to assume some level of uncertainty in the demand side (see, for instance, Klemperer and Meyer 1986). Indeed, by submitting supply functions, firms adapt better to changing conditions. Once the resolution of uncertainty takes place, a unique market equilibrium is reached where the aggregate supply function meets consumer demand. ${ }^{7}$ We denote by $p$ the market price and $q_{i}$ firm $i$ 's electric power generation, for $i=0,1, \ldots, n, q=\left(q_{0}, q_{1}, \ldots, q_{n}\right) \in \mathbb{R}_{+}^{n+1}$ and $Q=\sum_{i=0}^{n} q_{i}$. The representative consumer maximizes her surplus $C S(Q)=U(Q)-p Q$, yielding an aggregate demand $D(p)=\alpha-p+\varepsilon$, where $U(Q)=(\alpha+\varepsilon) Q-Q^{2} / 2$ is the utility function and $\varepsilon$ is an additive shock with strictly positive density $f(\varepsilon)$ everywhere on the support $\Omega \subset \mathbb{R}_{+}$such that $E(\varepsilon)=0$ and $V(\varepsilon)=\sigma^{2}$. In line with the literature, social welfare is assumed to be consumer surplus plus generators' profits. Firms bear a quadratic cost function $^{8}$ given by $C_{i}\left(q_{i}\right)=(c / 2) q_{i}^{2}$, with $c>0$. We assume that the state-owned 
generator and the private generators have the same level of efficiency because electric power generation technology is widespread and accessible regardless of the ownership of the firm.

Competition takes place as follows. Generators submit supply functions to the market (price-quantity pairs) that we assume to be continuous according to the linear ${ }^{9}$ function $q_{i}=\beta_{i} p$. We denote $\beta=\left(\beta_{0}, \beta_{1}, \ldots, \beta_{n}\right) \in \mathbb{R}^{n+1}$ and $\beta_{-j} \in \mathbb{R}^{n}$ the vector containing all the components of $\beta$ except $\beta_{j}$. Ex-ante market clearing conditions yield prices

$$
p(\beta)=(\alpha+\varepsilon) \cdot \frac{1}{1+\sum_{i=0}^{n} \beta_{i}} .
$$

Taking (1), a supply function of generator $i \in 0,1, \ldots, n$ is then given by

$$
q_{i}(\beta)=\beta_{i} p(\beta)
$$

Consequently, total electric power produced and traded is given by $Q(\beta)=\sum_{i=0}^{n} q_{i}(\beta)$. Each generator chooses a strategy by fixing its supply function's slope $\beta_{i} \geq 0$ which determines the amount of electric power generated at any market price $p$. On the one hand, the stateowned generator, which is assumed to be (partially) privatized according to the parameter $\lambda \in[0,1]$, maximizes the expected utility function that ranges between the social welfare when $\lambda=1$ (the generator behaves as a pure state-owned firm) and its own profits when $\lambda=0$ (the generator is fully privatized), that is,

$$
\max _{\beta_{0} \geq 0} \int_{\Omega}\left[\lambda S W(\beta)+(1-\lambda) \pi_{0}(\beta)\right] f(\varepsilon) d \varepsilon,
$$

where $S W(\beta)=C S(\beta)+\sum_{i=0}^{n} \pi_{i}(\beta)$ is the social welfare function, and $\pi_{i}(\beta)=p(\beta) q_{i}(\beta)-$ $C_{i}\left(q_{i}(\beta)\right)$ is the generator $i$ 's profit function, for $i \in\{0,1, \ldots, n\}$. On the other hand, private generators $j \in\{1,2, \ldots, n\}$ maximize their own expected profits,

$$
\max _{\beta_{j} \geq 0} \int_{\Omega} \pi_{j}(\beta) f(\varepsilon) d \varepsilon
$$

Observe that, taking into account (1) and (2), it is possible to rewrite generators' profits, consumer surplus, and social welfare as functions of $\beta$, namely,

$$
\begin{gathered}
\pi_{i}(\beta)=(\alpha+\varepsilon)^{2} \cdot \frac{\beta_{i}\left(2-c \beta_{i}\right)}{2\left(1+\sum_{i=0}^{n} \beta_{i}\right)^{2}}, \quad C S(\beta)=(\alpha+\varepsilon)^{2} \cdot \frac{\left(\sum_{i=0}^{n} \beta_{i}\right)^{2}}{2\left(1+\sum_{i=0}^{n} \beta_{i}\right)^{2}}, \\
S W(\beta)=(\alpha+\varepsilon)^{2} \cdot \frac{\left(\sum_{i=0}^{n} \beta_{i}\right)^{2}+2 \sum_{i=0}^{n} \beta_{i}-c \sum_{i=0}^{n} \beta_{i}^{2}}{2\left(1+\sum_{i=0}^{n} \beta_{i}\right)^{2}} .
\end{gathered}
$$

The strategic behaviour of the state-owned and private generators, derived from the first 
order conditions in (3) and (4), provides the best response functions:

$$
\begin{aligned}
\beta_{0}\left(\beta_{-0}\right)= & \frac{1+(1-\lambda) \sum_{i \neq 0}^{n} \beta_{i}+\lambda c \sum_{i \neq 0}^{n} \beta_{i}^{2}}{(1-\lambda)+c\left(1+\sum_{i \neq 0}^{n} \beta_{i}\right)}, \\
\beta_{j}\left(\beta_{-j}\right)= & \frac{1+\sum_{i \neq j}^{n} \beta_{i}}{1+c\left(1+\sum_{i \neq j}^{n} \beta_{i}\right)},
\end{aligned}
$$

that satisfy the appropriate second order sufficient conditions. From now on, we shall assume that all the private generators are symmetric in the sense that $\beta_{j}=\beta_{r}$ (hence, $q_{j}=q_{r}$ ) for all $j, r \in\{1, \ldots, n\}$. Consequently, the symmetry among private generators makes that the above best responses come down to

$$
\begin{aligned}
\beta_{0}\left(\beta_{j}\right) & =\frac{1+(1-\lambda) n \beta_{j}+\lambda c n \beta_{j}^{2}}{1-\lambda+c\left(1+n \beta_{j}\right)}, \\
\beta_{r}\left(\beta_{0}, \beta_{j}\right) & =\frac{1+\beta_{0}+(n-1) \beta_{j}}{1+c\left(1+\beta_{0}+(n-1) \beta_{j}\right)},
\end{aligned}
$$

which yield the optimal strategies reported in the following theorem.

Theorem 1. The optimal supply functions for the state-owned and (symmetric) private generators are

$$
\begin{aligned}
& \beta_{0}^{*}(n, c, \lambda)=\frac{(n-1) c \xi^{2}+(2+c-n) \xi-1}{1-c \xi}, \\
& \beta_{r}^{*}(n, c, \lambda)=\xi
\end{aligned}
$$

where $\xi$ is the unique positive value satisfying $a_{3} \xi^{3}+a_{2} \xi^{2}+a_{1} \xi+a_{0}=0$ with

$$
\begin{aligned}
& a_{3}=n c^{2}(n-1+\lambda), \\
& a_{2}=-c\left(n^{2}+(3 \lambda-2 c-4) n+c+1-\lambda\right), \\
& a_{1}=-2(c+1-\lambda) n+c(c+4-\lambda)+2(1-\lambda), \\
& a_{0}=\lambda-2-c .
\end{aligned}
$$

It is interesting to report the case in which $\lambda=0$, that is, when the state-owned generator is fully privatized and thus, the model is a pure supply function oligopoly with $n+1$ private generators. In this case, as the following proposition shows, the symmetric optimal strategy for the $n+1$ generators collapses to

$$
\vartheta(n, c):=\frac{n-c-1+\sqrt{(n-c-1)^{2}+4 n c}}{2 n c}
$$

for every $n \in \mathbb{N}$ and $c>0$. This value coincides with the result in Delbono and Lambertini (2016), which in turn was previously reported in Ciarreta and Gutiérrez-Hita (2006). The following proposition states two technical issues that help us to further present the main results of the paper. 
Proposition 1. Let $n \in \mathbb{N}, c>0$ and consider $\vartheta(n, c)$ as defined in (7). It holds that $\{\vartheta(n, c)\}_{n \in \mathbb{N}}$ is an increasing sequence of positive numbers and

(i) $\frac{1}{c+1}<\vartheta(n, c)<\beta_{r}^{*}(n, c, \lambda)<\vartheta(n+1, c)<\frac{1}{c}$ for all $\lambda \in(0,1]$.

(ii) $\beta_{0}^{*}(n, c, 0)=\beta_{r}^{*}(n, c, 0)=\vartheta(n, c)$.

The intuition behind Proposition 1 is twofold. First, as the number of private power generators increases their behaviour is more pro-competitive $\left(\beta_{r}^{*}(n, c, \lambda)\right.$ increases). Second, in the extreme case where the state-owned firm is totally privatized, its behaviour coincides with that of the private power generators, no matter the number of firms $n$, and the level of efficiency $c$. We also see from this result that $\beta_{0}^{*}(n, c, \lambda)$ in Theorem 1 is well-defined. Indeed, for the case $\lambda \in(0,1]$ (it is obvious from $(i i)$ if $\lambda=0)$ and having $\beta_{r}^{*}(n, c, \lambda)=\xi$ as in (6), one gets $1-c \xi>0$ and $(n-1) c \xi^{2}+(2+c-n) \xi-1>0$ from $(i)$ above, where the last inequality, for $n \geq 2$, follows from the fact that $\vartheta(n-1, c) \leq \vartheta(n, c)<\xi$ and $(n-1) c>0$, and for $n=1$, it follows since $1<(c+1) \xi$. Furthermore, since $\beta_{0}$ just depends on $\beta_{r}$ according to (5), then one can equivalently write the formula for $\beta_{0}^{*}(n, c, \lambda)$ in (6) as

$$
\beta_{0}^{*}(n, c, \lambda)=\frac{1+(1-\lambda) n \xi+\lambda c n \xi^{2}}{1-\lambda+c(1+n \xi)} .
$$

Before introducing the discussion on the level of privatization of the state-owned generator, the effect of free entry, and the level of marginal cost, it is interesting to present some particular cases of our model. Firstly, we note that the mixed duopoly model with differentiated products studied in Gutiérrez-Hita and Vicente-Pérez (2018) is somehow a particular case of our model for the case $\lambda=1, n=1$, and $c=1$, but including a parameter $\gamma$ to capture the degree of product differentiation. And secondly, it is also interesting to consider as a benchmark case the model with a pure state-owned generator and $n$ private generators, in order to compare it with the generalized model that we will introduce in the following section where partial privatization will be considered. In this respect, a simple duopoly model with a state-owned firm and a private firm can be found in Yasui and Haraguchi (2018), where the authors state that a full public firm provides the highest social welfare. In our model though, we allow for an arbitrary number $n$ of private generators, which has a direct impact on market behaviour. Letting $\lambda=1$, the optimal strategies in (6) become

$$
\beta_{0}^{*}(n, c, 1)=\frac{1+n c \xi^{2}}{c(1+n \xi)}, \quad \beta_{r}^{*}(n, c, 1)=\xi
$$

where, according to Theorem $1, \xi$ is the unique positive value satisfying $n^{2} c^{2} \xi^{3}-c\left(n^{2}-\right.$ $(2 c+1) n+c) \xi^{2}+c(c+3-2 n) \xi=1+c$. Here, it is interesting to note that as the number of generators increases the strategic behaviour of the fully state-owned generator mimics the ones followed by the private generators, since $\lim _{n \rightarrow+\infty} \beta_{0}^{*}(n, c, 1)=\xi$. Thus, social welfare could be higher if free entry is allowed. However, in electric power generation, entry barriers are present for a number of reasons: technical restrictions, licenses, and access to financial markets to invest in generation equipment. Then, in practice, electric power oligopolies include a reduced number of power generators. In what follows, we will use our model to investigate how the level of privatization and the number of generators can be used as a way to enhance consumer surplus and social welfare. 
According to Theorem 1, the optimal strategy of the state-owned generator depends on the symmetric optimal strategies of the $n$ private generators. Thus, optimal market price, electric power traded, generators' profits, consumer surplus, and social welfare can be presented also as functions of $\beta_{r}^{*}(n, c, \lambda)=\xi$, namely,

$$
\begin{aligned}
p^{*}(n, c, \lambda) & =(\alpha+\varepsilon) \cdot \frac{1-c \xi}{\xi(2-c \xi)}, \\
q_{0}^{*}(n, c, \lambda) & =(\alpha+\varepsilon) \cdot \frac{(n-1) c \xi^{2}+(2+c-n) \xi-1}{\xi(2-c \xi)}, \\
q_{r}^{*}(n, c, \lambda) & =(\alpha+\varepsilon) \cdot \frac{1-c \xi}{2-c \xi}, \\
\pi_{0}^{*}(n, c, \lambda) & =(\alpha+\varepsilon)^{2} \cdot \frac{\left((n-1) c \xi^{2}+(2+c-n) \xi-1\right)\left(c^{2}(1-n) \xi^{2}+c(n-c-4) \xi+2+c\right)}{2 \xi^{2}(2-c \xi)^{2}}, \\
\pi_{r}^{*}(n, c, \lambda) & =(\alpha+\varepsilon)^{2} \cdot \frac{(1-c \xi)^{2}}{2 \xi(2-c \xi)}, \\
C S^{*}(n, c, \lambda) & =(\alpha+\varepsilon)^{2} \cdot \frac{\left(c \xi^{2}-(2+c) \xi+1\right)^{2}}{2 \xi^{2}(2-c \xi)^{2}}, \\
S W^{*}(n, c, \lambda) & =\left(C S^{*}+\pi_{0}^{*}+n \cdot \pi_{r}^{*}\right)(n, c, \lambda) .
\end{aligned}
$$

\section{Partial privatization, free entry, and cost variation}

In this section, we present the main results of the paper. We shall study the asymptotic behaviour of generators' optimal strategies $\beta_{0}^{*}(n, c, \lambda)$ and $\beta_{r}^{*}(n, c, \lambda)$ whenever the degree of privatization, the number of generators, or the cost parameter changes, all other things being equal. As a result of the asymptotic behaviour of the optimal strategies, market outcomes, consumer surplus, and social welfare, also change.

\subsection{Variation in the degree of privatization}

In what follows we study how optimal strategies change with the degree of privatization. Liberalization of electric power generation opens a debate about the extent to which a stateowned generator, the former monopolist, should be privatized. Obviously, it implies different levels of consumer surplus.

Proposition 2. For every $(n, c, \lambda) \in \mathbb{N} \times(0,+\infty) \times(0,1)$ one has

$$
\frac{\partial \beta_{0}^{*}(n, c, \lambda)}{\partial \lambda}>\frac{\partial \beta_{r}^{*}(n, c, \lambda)}{\partial \lambda}>0 .
$$

This result states that given a number of electric power generators $n$ and a cost parameter value $c$, as the partially privatized state-owned generator becomes less private, all generators exert lower market power. In particular, the state-owned generator has lower market power than the one exerted by private generators. In the opposite case, when the state-owned generator is fully privatized, the $n+1$ private generators mimic a pure supply function oligopoly (see Figure 1) and the results obtained in Ciarreta and Gutiérrez-Hita (2006) arise. Intuitively, one could argue that if the goal of the government is to enhance consumer surplus, privatization is not advised since it induces generators to behave less aggressively in the market. 


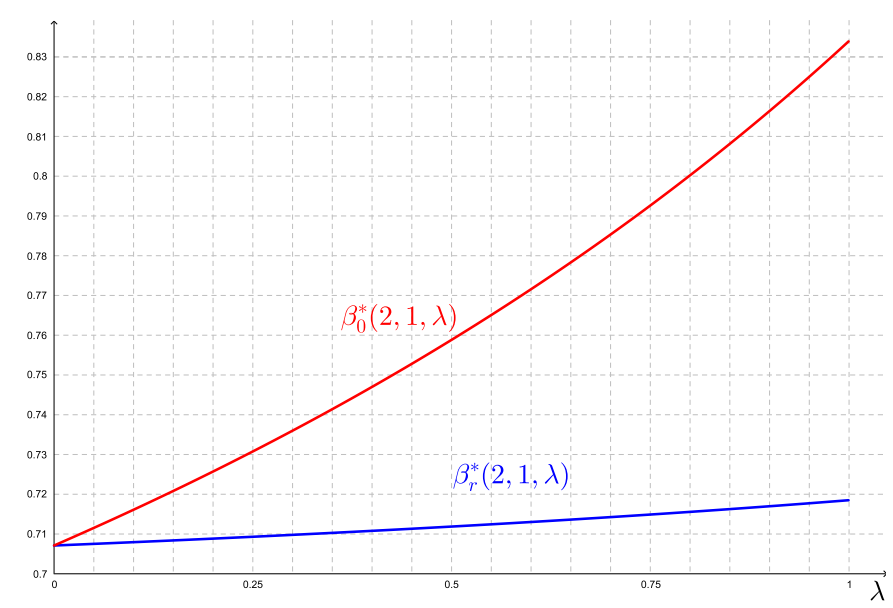

Figure 1: Optimal supply functions $\beta_{0}^{*}(2,1, \lambda)$ and $\beta_{r}^{*}(2,1, \lambda)$.

\subsection{Variation in the number of generators}

We consider here the effect of variations in the number of generators in choosing their optimal strategies. Intuitively, as the number of generators increases, competition is enhanced and therefore, generators behave more aggressively.

Proposition 3. For every $(n, c, \lambda) \in \mathbb{N} \times(0,+\infty) \times[0,1]$ one has:

(i) If $\lambda>0$, then $\beta_{r}^{*}(n, c, 0)<\beta_{r}^{*}(n, c, \lambda)<\beta_{r}^{*}(n+1, c, 0)$.

(ii) If $\lambda>0$, then $\beta_{r}^{*}(n, c, \lambda)<\beta_{0}^{*}(n, c, \lambda)$.

(iii) $\beta_{r}^{*}(n, c, \lambda)<\beta_{r}^{*}(n+1, c, \lambda)$.

(iv) $\lim _{n \rightarrow+\infty} \beta_{r}^{*}(n, c, \lambda)=\lim _{n \rightarrow+\infty} \beta_{0}^{*}(n, c, \lambda)=\frac{1}{c}$.

Firstly, this result states that an increase in the number of generators always yields to a more competitive behaviour by the private generators than keeping the state-owned generator fully or partially in public hands. In other words, liberalization provides the first best result in terms of consumer surplus. Secondly, if the state-owned generator is not fully privatized, then it always behaves more aggressively than private generators. It is also shown that, since the state-owned generator is (to some extent) a social welfaremaximizer, it has an incentive to increase output in order to reduce the market price and, therefore, the state-owned generator's optimal supply function is always above the one chosen by the private generators. This pro-competitive effect followed by the state-owned firm as the number of firms increases is also noted by De Fraja and Delbono (1989) in a Cournot framework. Moreover, we also note that for every level of privatization an increase in the number of entrants enhance competitiveness and consequently, the market price decreases and consumer surplus increases. Finally, for a sufficiently high number of generators, the state-owned and private generators' strategies converge to the inverse of the marginal cost parameter, minimizing thus generators' profits.

Remark 1. Numerical simulations suggest that $\beta_{0}^{*}(n, c, \lambda)<\beta_{0}^{*}(n+1, c, \lambda)$ and furthermore $\beta_{0}^{*}(n, c, \lambda)-\beta_{r}^{*}(n, c, \lambda) \geq \beta_{0}^{*}(n+1, c, \lambda)-\beta_{r}^{*}(n+1, c, \lambda)$ for all $(n, c, \lambda) \in \mathbb{N} \times(0,+\infty) \times[0,1]$, 
having that $\left\{\beta_{0}^{*}(n, c, \lambda)-\beta_{r}^{*}(n, c, \lambda)\right\}_{n \in \mathbb{N}}$ is a decreasing sequence of non-negative numbers such that

$$
\lim _{n \rightarrow+\infty} \beta_{0}^{*}(n, c, \lambda)-\beta_{r}^{*}(n, c, \lambda)=0
$$

as a consequence of Proposition $3(i v)$.

Indeed, it is also interesting to note that the asymptotic behaviour of the optimal strategies towards $1 / c$ as the number of firms increases means that price approaches marginal cost and then, perfect competition is reached and social welfare is maximized.

\subsection{Variation in the cost parameter}

Changes in the cost functions might be due, for instance, to a variation in the price of the inputs. In particular, the electric power generation is probably more sensitive than other markets in this respect. Sometimes, to generate power at peak demand hours can be difficult because the cheapest plants are capacity constrained and consequently, it is necessary to generate power with those plants with expensive inputs (like fuel, for instance). In other cases, the lack of wind, rain or ultraviolet rays makes it almost impossible to generate power by renewable plants. In our model, this effect might be captured by the parameter $c$. The following proposition describes the optimal behaviour of generators as a result of a change in this parameter.

Proposition 4. For every $(n, c, \lambda) \in \mathbb{N} \times(0,+\infty) \times[0,1]$ one has:

(i) $\frac{\partial \beta_{0}^{*}(n, c, \lambda)}{\partial c} \leq \frac{\partial \beta_{r}^{*}(n, c, \lambda)}{\partial c} \leq 0$.

(ii) $\lim _{c \rightarrow 0^{+}} \beta_{r}^{*}(n, c, \lambda)=\lim _{c \rightarrow 0^{+}} \beta_{0}^{*}(n, c, \lambda)=+\infty$.

(iii) $\lim _{c \rightarrow+\infty} \beta_{r}^{*}(n, c, \lambda)=\lim _{c \rightarrow+\infty} \beta_{0}^{*}(n, c, \lambda)=0$.

The main result enclosed in Proposition 4 states that if $c$ increases, generators enlarge price-cost margins; in particular, private generators exert more market power than the stateowned generator. As a consequence, consumer surplus decreases. In addition, when the level of $c$ is close to zero, generators' behaviour resembles the one under perfect competition (notice that $\left.\lim _{c \rightarrow 0^{+}} 1 / c=+\infty\right)$. Finally, the intuition of the third statement is that, if $c$ is extremely large, market power is extremely high, and consequently, generators may impose excessive prices.

\section{State-owned generator versus free entry}

Liberalization usually implies that entry barriers have to be minimized or almost eliminated in order to increase the number of electric power generators. In addition, it often implies that the former state-owned monopolist is also privatized. This seems to be the wave observed within the OECD countries, where mixed oligopolies have passed, and pure private oligopolies have emerged. The question arises, therefore, of what happens, in terms of consumer surplus and generators' profits, in the transition from a state-owned generator towards a market with private generators. In our model, this issue can be studied by comparing the 
market outcome at $\lambda=1$ and $\lambda=0$. If the goal of the state is to protect consumer surplus, the privatization of the former state-owned generator may yield a more competitive market and thus, enhancing consumer surplus. Conversely, the privatization of the state-owned generator may enhance generators' profits lowering consumer surplus if the number of generators is low enough. In the following proposition, we present the effect of the privatization on the market outcomes of our model.

Proposition 5. Keeping fixed the number of generators and the cost parameter, when the level of privatization decreases $(\lambda \rightarrow 1)$ one has:

$$
\frac{\partial p^{*}}{\partial \lambda}<0, \quad \frac{\partial q_{r}^{*}}{\partial \lambda}<0, \quad \frac{\partial q_{0}^{*}}{\partial \lambda}>0, \quad q_{r}^{*} \leq q_{0}^{*}
$$

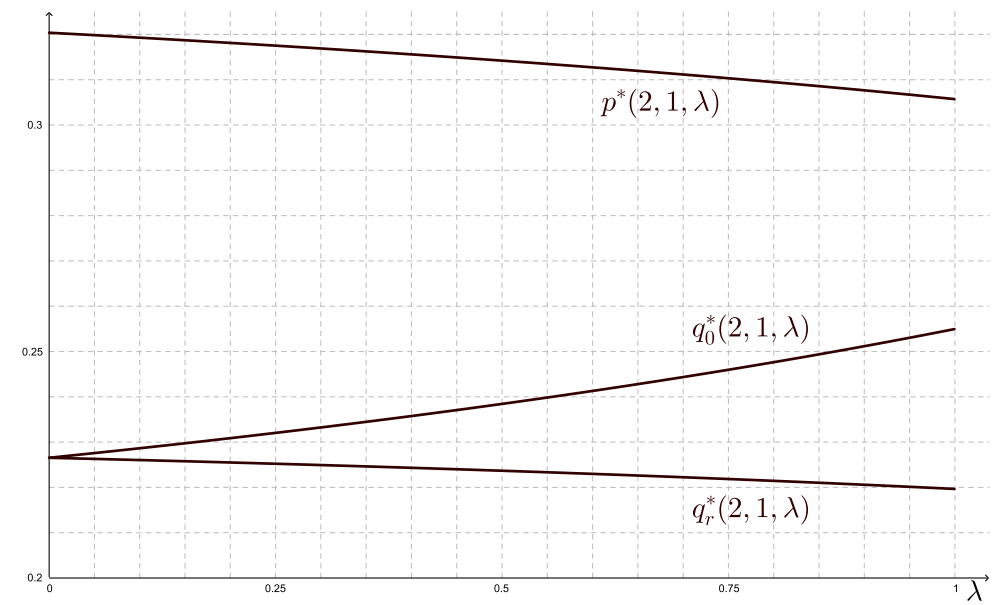

Figure 2: (expected) optimal price and quantities (assuming $\alpha=1$ ).

Observing Figure 2 and from Proposition 5, one can note that consumer surplus increases in $\lambda$, since, for a given number of generators, as the state-owned generator becomes less private, the price decreases. In addition, although the amount of electric power generated by private generators also decreases, it is not low enough to compensate the output increase from the state-owned generator and, as a consequence, the total quantity generated increases. In what follows, we present the main result of this section. Later on, we conduct a numerical simulation in order to highlight these results.

Proposition 6. Keeping fixed the number of generators and the cost parameter, a fully privatized state-owned generator $(\lambda=0)$ is the best policy to maximize generators' profits, as

$$
\frac{\partial \pi_{r}^{*}}{\partial \lambda}<0, \quad \frac{\partial \pi_{0}^{*}}{\partial \lambda}<0, \quad \pi_{r}^{*} \leq \pi_{0}^{*} .
$$

However, a pure state-owned generator $(\lambda=1)$ is the best policy to maximize consumer surplus and social welfare, as

$$
\frac{\partial C S^{*}}{\partial \lambda}>0, \quad \frac{\partial S W^{*}}{\partial \lambda}>0
$$

These results are in line with those recently stated by Yasui and Haraguchi (2018) in a similar environment. ${ }^{10}$ In particular, if firms compete in supply functions, any level of 


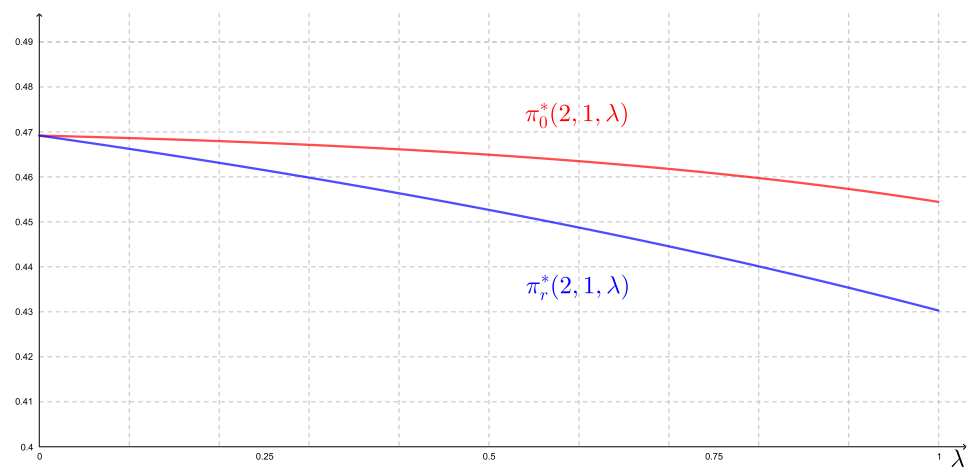

Figure 3: (expected) optimal profits (assuming $\alpha^{2}+\sigma^{2}=10$ ).

privatization makes the partially state-owned firm less aggressive, inducing private firms also to behave less aggressively as well. Social welfare decreases because profit increases are lower than the reduction of consumer surplus due to a higher price and a lower amount of electricity traded, resulting from higher market power. Conversely, when the state-owned generator remains in public hands, social welfare increases because, although generators' profits decrease (see Figure 3), consumer surplus increases compensating the damage imposed on generators' profits due to a lower price and a higher amount of electric power generated (see Figure 2). Indeed, since the marginal cost increases with the amount of output produced, a lower price-cost margin is obtained. In other words, for a given number of generators, an increase in the level of government participation in the state-owned generator is positive in order to enhance electric power generation at moderate prices.

Hereinafter, we present the results concerning potential simultaneous variations in the level of privatization and in the number of generators. Our results suggest that there is a trade-off between these two parameters. As the model does not provide explicit functions to check this insight, we conduct numerical simulations in order to check differences in market outcomes between total privatization $(\lambda=0)$ and a pure mixed oligopoly $(\lambda=1)$ for $n=\{1,3,5,10\}$. Without loss of generality, we take $\alpha^{2}+\sigma^{2}=10$ and $c=1$. First, let us present the effect of $\lambda$ and $n$ in the consumer surplus. Our simulations show that $C S(n, 1,1)>C S(n, 1,0)$. After privatization, it is thus always necessary to increase the number of generators to get the same level of consumer surplus of a pure mixed oligopoly, i.e., $C S(n, 1,1)=C S(\hat{n}, 1,0)$ for some $\hat{n}>n$. To avoid integer problems, the number of generators is treated as a continuous variable. Table 1 includes these numerical simulations.

\begin{tabular}{|c|c|c|}
\hline$\lambda=1$ & $C S$ & $\lambda=0$ \\
\hline \hline$n=1$ & 1.812 & $\hat{n}=1.32$ \\
\hline$n=3$ & 2.883 & $\hat{n}=3.09$ \\
\hline$n=5$ & 3.487 & $\hat{n}=5.04$ \\
\hline$n=10$ & 4.133 & $\hat{n}=10.001$ \\
\hline
\end{tabular}

Table 1: $C S$, privatization, and $n$.

Second, we focus on the social welfare, where $S W(n, 1,1)>S W(n, 1,0)$. It is also necessary to increase the number of generators to get the same level of social welfare of a pure mixed oligopoly, i.e., $S W(\bar{n}, 1,1)=S W(n, 1,0)$ for some $\bar{n}>n$. We notice that the number of 
generators that meet the level of social welfare under a mixed oligopoly is lower than the one needed to get the equivalent level of consumer surplus. This is because market power exerted by the private oligopoly is higher when the number of generators decreases and thus, it further enhances private firms' profits at the cost of reducing consumer surplus. Table 2 includes these numerical simulations.

\begin{tabular}{|c|c|c|}
\hline$\lambda=1$ & $S W$ & $\lambda=0$ \\
\hline \hline$n=1$ & 3.284 & $\bar{n}=1.07$ \\
\hline$n=3$ & 3.988 & $\bar{n}=3.01$ \\
\hline$n=5$ & 4.282 & $\bar{n}=5.001$ \\
\hline$n=10$ & 4.583 & $\bar{n}=10.0001$ \\
\hline
\end{tabular}

Table 2: $S W$, privatization, and $n$.

In order to enhance consumer surplus, it is necessary to increase the number of generators. If the number of generators in a private oligopoly is lower, private generators' profits are surely enhanced but consumer surplus will be lower than the one obtained in a mixed oligopoly. In other words, if the goal of the government is to protect consumer surplus, competition should be enhanced through an increase in the number of generators, and thus, lowering entry barriers, or instead, keeping the state-owned generator in public hands. Our results also suggest that, since electric power generation is often characterized by a reduced number of generators competing in the market due to the high technological and regulatory entry barriers, a compelling argument to maintain certain levels of public equities in the former state-owned from partially privatized firms can be used.

\section{Conclusions}

Although liberalization was intended to enhance competition and, consequently, to provide electric power at moderate prices without interruptions in the service, this does not seem to be the case in many countries. Two features contribute to understanding this observation: demand is often almost perfectly inelastic, and the market is highly concentrated. Indeed, in the last twenty years, demand has increased and the entry barriers were maintained, yielding higher generators' market shares in narrow oligopolies.

We have presented in this paper a mixed oligopoly model where generators compete in a supply function fashion, and where the state-owned generator can be partially (even fully) privatized. In this context, consumer surplus and social welfare are enhanced when the entry cost is low enough or, alternatively, when the state maintains the former generator's monopolist as a state-owned generator. Moreover, when cost increases, generators apply higher price-cost margins yielding an increase in their market power. Our results suggest that those countries where electric generation is provided by a few generators, the state should probably control a significant volume of equities of the partially privatized stateowned generator. Besides, it seems that an appropriate policy could also be to manage a regulatory body of rules aimed to increase competition by entering more generators in the market especially whenever the former incumbent has been almost fully privatized.

As a matter of fact, the framework we have worked with represents a particular approach to a more general issue. To analyze a real-world electricity system, further research is required. As mentioned above, the results of this paper imply that the optimal policy 
could be the nationalization of a public generator, and at the same time, removing entry barriers. Possible extensions include a dynamic model with entering that could explain the privatization of public generators. For example, the regulator could commit to either privatize the public generator or not and, later, private firms could decide either to enter or not, incurring, in the former case, a fixed entry cost. In this setting, entry could only occur if the government commits to privatization. ${ }^{11}$ Additionally, incorporating spillovers in the case of a privatization policy affecting the production cost, or cross-ownership would probably enrich our analysis. We believe that those are subjects for future research.

\section{Acknowledgements}

The authors are grateful to the associate editor and three anonymous reviewers for helpful comments which have contributed to the final preparation of the paper. We also are grateful for suggestions and comments received in a parallel session at the XXXIII Jornadas de Economía Industrial, held in Barcelona on September 2018. 


\section{References}

Anderson, S. P., de Palma, A., and Thisse, J.-F. (1997). Privatization and efficiency in a differentiated industry. European Economic Review, 41(9):1635-1654.

Balza, L., Jimenez, R., and Mercado, J. (2013). Privatization, institutional reform, and performance in the latin american electricity sector. Technical Report No. IDB-TN-599, Inter-American Development Bank. Energy Division INE/ENE.

Borenstein, S. and Bushnell, J. (1999). An empirical analysis of the potential for market power in California's electricity industry. Journal of Industrial Economics, XLVII(3):285323.

Ciarreta, A. and Gutiérrez-Hita, C. (2006). Supply function vs quantity competition in supergames. International Journal of Industrial Organization, 24(4):773-783.

Ciarreta, A. and Gutiérrez-Hita, C. (2012). Collusive behaviour under cost asymmetries when firms compete in supply functions. Journal of Economics, 106(3):195-219.

Day, C. J., Hobbs, B. F., and Pang, J.-S. (2002). Oligopolistic competition in power networks: A conjectured supply function approach. IEEE Transactions on Power Systems, 17(3):597-607.

De Fraja, G. and Delbono, F. (1989). Alternative strategies of a public enterprise in oligopoly. Oxford Economics Papers, 41(2):302-311.

De Fraja, G. and Delbono, F. (1990). Game theoretic models of mixed oligopoly. Journal of Economics Surveys, 4(1):1-17.

Delbono, F. and Lambertini, L. (2015). On the properties of linear supply functions in oligopoly. Economics Letters, 136:22-24.

Delbono, F. and Lambertini, L. (2016). Ranking Bertrand, Cournot and supply function equilibria in oligopoly. Energy Economics, 60:73-78.

Delbono, F. and Lambertini, L. (2018). Choosing roles under supply function competition. Energy Economics, 71:83-88.

Fisher, R. and Serra, P. (2004). Efectos de la privatización de servicios públicos en Chile: casos sanitario, electricidad y telecomunicaciones. Technical Report RE1-04-017, Banco Interamericano de Desarrollo.

Futagami, K., Matsumura, T., and Takao, K. (2019). Mixed duopoly: Differential game approach. Journal of Public Economic Theory, 21(4):771-793.

Green, R. (1996). Increasing competition in the british electricity spot market. Journal of Industrial Economics, XLIV(2):205-216.

Green, R. (1999). The electricity contract market in england and wales. Journal of Industrial Economics, XLVII(1):107-124. 
Green, R. J. and Newbery, D. M. (1992). Competition in the british electricity spot market. Journal of Political Economy, 100(5):929-953.

Gutiérrez-Hita, C. and Vicente-Pérez, J. (2018). On supply function equilibria in a mixed duopoly. Economics Letters, 168:6-9.

Holmberg, P. and Newbery, D. (2010). The supply function equilibrium and its policy implications for wholesale electricity auctions. Utilities Policy, 18(4):209-226.

Holmberg, P., Newbery, D., and Ralph, D. (2013). Supply function equilibria: Steps functions and continuous representations. Journal of Economic Theory, 148(4):1509-1551.

Hyman, L. S. (2010). Restructuring electricity policy and financial models. Energy Economics, 32(4):751-757.

Jamasb, T. and Pollitt, M. (2005). Electricity market reform in the european union: Review of progress toward liberalization and integration. The Energy Journal, 26:11-41.

Klemperer, P. D. and Meyer, M. A. (1986). Price competition vs. quantity competition: the role of uncertainty. The RAND Journal of Economics, 17(4):618-638.

Klemperer, P. D. and Meyer, M. A. (1989). Supply function equilibria in oligopoly under uncertainty. Econometrica, 57(6):1243-1277.

Kronqvist, J., Bernal, D. E., Lundell, A., and Grossmann, I. E. (2019). A review and comparison of solvers for convex MINLP. Optimization and Engineering, 20(2):397-455.

Matsumura, T. (1998). Partial privatization in mixed duopoly. Journal of Public Economics, $70(3): 473-483$.

Matsumura, T. and Kanda, O. (2005). Mixed oligopoly at free entry markets. Journal of Economics, 84(1):27-48.

Menezes, F. M. and Pereira, J. (2017). Emissions abatement R\&D: Dynamic competition in supply schedules. Journal of Public Economic Theory, 19(4):841-859.

Newbery, D. M. and Greve, T. (2017). The strategic robustness of oligopoly electricity market models. Energy Economics, 68:124-132.

Sahinidis, N. V., Ryoo, H., Shectman, J., Ghildyal, V., Tamarmalani, M., Bao, X., Khajavirad, A., Zorn, K., Puranik, Y., and Kilinç, M. (2018). BARON version 18.5.9. The Optimization Firm, LCC.

Vives, X. (2011). Strategic supply function competition with private information. Econometrica, 79(6):1919-1966.

Wolfram, C. D. (1999). Measuring duopoly power in the British electricity spot market. American Economic Review, 89(4):805-826.

Yasui, Y. and Haraguchi, J. (2018). Supply function equilibria and nonprofit-maximizing objectives. Economics Letters, 166:50-55. 


\section{Appendix}

\section{Proofs of the main results}

Proof of Theorem 1.

Given $(n, c, \lambda) \in \mathbb{N} \times(0,+\infty) \times[0,1]$, the optimal supply functions $\beta_{0}^{*}(n, c, \lambda)$ and $\beta_{r}^{*}(n, c, \lambda)$ in $(6)$ are obtained by combining the equations in (5). Let

$$
P_{n, c, \lambda}(x):=a_{3} x^{3}+a_{2} x^{2}+a_{1} x+a_{0} .
$$

Since $P_{n, c, \lambda}(0)=a_{0}<0$ and $\lim _{x \rightarrow+\infty} P_{n, c, \lambda}(x)=+\infty$ (observe that $a_{3}>0$ except for $n=1$ and $\lambda=0$, in which case $a_{3}=0$ and $a_{2}=c^{2}+2 c>0$ ), in virtue of the well-known Bolzano's Theorem one gets that $P_{n, c, \lambda}$ has a positive root, say $\xi$ depending on $(n, c, \lambda)$.

Next we prove that the equilibrium given in (6) is unique. We just need to show that the polynomial $P_{n, c, \lambda}$ has a unique positive root. For that purpose, we apply differentiation and study the polynomial $P_{n, c, \lambda}^{\prime}(x)=3 a_{3} x^{2}+2 a_{2} x+a_{1}$ in order to analyze the monotonicity and stationary points of $P_{n, c, \lambda}$. Let assume that $n \neq 1$ or $\lambda \neq 0$, and so $a_{3}>0$. Otherwise, it is easy to see that $\vartheta(1, c)$ is the unique positive root of $P_{1, c, 0}$. Thus, $P_{n, c, \lambda}^{\prime}(0)=a_{1}$ and $P_{n, c, \lambda}^{\prime}(x)=0$ if and only if $x=\frac{-a_{2} \pm \sqrt{\Delta}}{3 a_{3}}$ where $\Delta:=a_{2}^{2}-3 a_{1} a_{3}$. We discuss the following cases:

- If $a_{1}<0$, then $\Delta>a_{2}^{2} \geq 0$ and $P_{n, c, \lambda}$ has two stationary points with different sign, say $\underline{x}<0$ and $\bar{x}>0$. This means that $P_{n, c, \lambda}$ is strictly decreasing in $(0, \bar{x})$ and strictly increasing in $(\bar{x},+\infty)$, and so it has a unique positive root.

- If $a_{1} \geq 0$ and $\Delta<0$, then $P_{n, c, \lambda}$ has no stationary points and it is strictly increasing in $\mathbb{R}$, which shows that it has a unique positive root.

- If $a_{1} \geq 0$ and $\Delta \geq 0$, then we get $a_{2} \geq 0$. This follows from the fact that

$$
\inf \left\{a_{2}: a_{1} \geq 0, \Delta \geq 0, n \in \mathbb{N}, c \geq 0, \lambda \in[0,1]\right\}=0,
$$

obtained by using the software BARON. ${ }^{12}$ Hence, in this case, $P_{n, c, \lambda}$ has (at most two) stationary points which are lower or equal than 0 , and so it is strictly increasing in $(0,+\infty)$, which shows again that $P_{n, c, \lambda}$ has a unique positive root.

We finally observe that in all of the three cases above one has $P_{n, c, \lambda}^{\prime}(\xi)>0$.

Proof of Proposition 1.

Fixed $c>0$, it can be checked (we omit the details) that $\frac{1}{c+1}<\vartheta(n, c)<\vartheta(n+1, c)<\frac{1}{c}$ for all $n \in \mathbb{N}$, and so, $\{\vartheta(n, c)\}_{n \in \mathbb{N}}$ is a (bounded) increasing sequence of positive numbers.

(i) Let $\lambda \in(0,1]$. Recalling the polynomial $P_{n, c, \lambda}$ introduced in Theorem 1 , one gets

$$
P_{n, c, \lambda}(\vartheta(n, c))=\frac{\lambda}{2 n^{2}}\left(2 n-(n+c+1)^{2}+(n+c+1) \sqrt{(n-c-1)^{2}+4 n c}\right)<0
$$

(being this inequality equivalent to $-4 n^{2}<0$ ) and

$$
P_{n, c, \lambda}(\vartheta(n+1, c))=\frac{1}{2 c(n+1)^{3}}(u \lambda+v) \geq \frac{1}{2 c(n+1)^{3}}(u+v) \geq \frac{1}{c(n+1)^{3}}>0
$$


where $u=6 c-2 n-3 n c^{2}+3 n c-n^{2}+2 c^{2}-c n^{2}-2 c^{2} n^{2}-n c^{3}-c n^{3}+\left(n^{2} c+n c^{2}+n c-2-2 c-n\right) \sqrt{w}$, $v=-3 n c^{2}-2 c n^{2}-4 n c+n^{2}-9 c^{2}-8 c+2 n+n^{3}-2 c^{3}+\left(n c+n+5 c+n^{2}+2 c^{2}+2\right) \sqrt{w}$ and $w=(n+c)^{2}+4 c$. The first two inequalities in (9) follow from the fact that $\lambda \in[0,1]$, $u \leq 0$ and $u+v \geq 2$ since

$$
\begin{aligned}
\sup \{u: n \in \mathbb{N}, c \geq 0\} & =0, \\
\inf \{u+v: n \in \mathbb{N}, c \geq 0\} & =2,
\end{aligned}
$$

again by using the software BARON. Hence, by applying again the Bolzano's Theorem one has that $\vartheta(n, c)<\beta_{r}^{*}(n, c, \lambda)<\vartheta(n+1, c)$.

(ii) If $\lambda=0$, one can write $P_{n, c, 0}(x)=\left(n c x^{2}+(1+c-n) x-1\right) \cdot((n-1) c x+2+c)$. The unique positive root of that polynomial is $\beta_{r}^{*}(n, c, 0)=\vartheta(n, c)$. The identity $\beta_{0}^{*}(n, c, 0)=$ $\beta_{r}^{*}(n, c, 0)$ follows as a consequence of the expression of $\beta_{0}^{*}(n, c, 0)$.

\section{Proof of Proposition 2.}

Let $\xi=\beta_{r}^{*}(n, c, \lambda)$. In order to compute $\frac{\partial \xi}{\partial \lambda}$, we use that $P_{n, c, \lambda}(\xi)=0$ and employ implicit differentiation. Consequently, we get that

$$
\frac{\partial \xi}{\partial \lambda}=-\frac{G_{n, c, \lambda}(\xi)}{P_{n, c, \lambda}^{\prime}(\xi)}
$$

where $G_{n, c, \lambda}(x):=\frac{\partial a_{3}}{\partial \lambda} x^{3}+\frac{\partial a_{2}}{\partial \lambda} x^{2}+\frac{\partial a_{1}}{\partial \lambda} x+\frac{\partial a_{0}}{\partial \lambda}=n c^{2} x^{3}+(-3 n c+c) x^{2}+(2 n-c-2) x+1$. The proof of Theorem 1 guarantees that $P_{n, c, \lambda}^{\prime}(\xi)>0$. Thus, we just need to show that $G_{n, c, \lambda}(\xi)<0$. Since $\lim _{x \rightarrow-\infty} G_{n, c, \lambda}(x)=-\infty, G_{n, c, \lambda}(0)=1>0, G_{n, c, \lambda}\left(\frac{1}{c}\right)=-\frac{1}{c}<0$ and $\lim _{x \rightarrow+\infty} G_{n, c, \lambda}(x)=+\infty$, then $G_{n, c, \lambda}$ has one negative root and two different positive roots. Furthermore, one has

$$
G_{n, c, \lambda}(\vartheta(n, c))=\frac{1}{2 n^{2}}\left(2 n-(n+c+1)^{2}+(n+c+1) \sqrt{(n-c-1)^{2}+4 n c}\right)<0
$$

and so, as $0<\vartheta(n, c)<\xi<\frac{1}{c}$ and $G_{n, c, \lambda}$ is continuous, then $G_{n, c, \lambda}(\xi)<0$ and so $\frac{\partial \xi}{\partial \lambda}>0$. Now,

$$
\frac{\partial\left(\beta_{0}^{*}-\beta_{r}^{*}\right)}{\partial \lambda}=\frac{\partial\left(\beta_{0}^{*}-\beta_{r}^{*}\right)}{\partial \xi} \cdot \frac{\partial \xi}{\partial \lambda}=\frac{-n c^{2} \xi^{2}+2 n c \xi+1-n}{(1-c \xi)^{2}} \cdot \frac{\partial \xi}{\partial \lambda}>0
$$

since $\frac{\partial \xi}{\partial \lambda}>0$ and $-n c^{2} \xi^{2}+2 n c \xi+1-n>0$. Observe that the last inequality is equivalent to $F_{n, c}(\xi)>0$ where $F_{n, c}(x):=-n c^{2} x^{2}+2 n c x+1-n$. Since $F_{n, c}(x)>0$ if and only if $x \in\left(\frac{n-\sqrt{n}}{n c}, \frac{n+\sqrt{n}}{n c}\right)$, and $\frac{n-\sqrt{n}}{n c}<\vartheta(n, c)<\xi<\frac{1}{c}<\frac{n+\sqrt{n}}{n c}$, then $F_{n, c}(\xi)>0$ and the conclusion follows.

\section{Proof of Proposition 3.}

(i) It is a straightforward consequence of Proposition 1.

(ii) Let $\lambda \in(0,1]$. The inequality $\beta_{r}^{*}(n, c, \lambda)<\beta_{0}^{*}(n, c, \lambda)$ is equivalent to

$$
\frac{n c \xi^{2}+(1+c-n) \xi-1}{1-c \xi}>0 .
$$


By Proposition 1 one has $1-c \xi>0$ and $n c \xi^{2}+(1+c-n) \xi-1>0$ since $\vartheta(n, c)<\xi$ and $n c>0$. Thus, the claimed inequality holds.

(iii) It easily follows from Proposition 1 since $\beta_{r}^{*}(n, c, \lambda)<\vartheta(n+1, c)<\beta_{r}^{*}(n+1, c, \lambda)$ if $\lambda>0$, and the fact that $\{\vartheta(n, c)\}_{n \in \mathbb{N}}$ is a strictly increasing sequence and so $\beta_{r}^{*}(n, c, 0)=$ $\vartheta(n, c)<\vartheta(n+1, c)=\beta_{r}^{*}(n+1, c, 0)$.

(iv) As $\vartheta(n, c)<\beta_{r}^{*}(n, c, \lambda)<\frac{1}{c}$, then one has

$$
\frac{1}{c}=\lim _{n \rightarrow+\infty} \vartheta(n, c) \leq \lim _{n \rightarrow+\infty} \beta_{r}^{*}(n, c, \lambda) \leq \frac{1}{c}
$$

and so $\lim _{n \rightarrow+\infty} \beta_{r}^{*}(n, c, \lambda)=\frac{1}{c}$. Now we claim $\beta_{0}^{*}(n, c, \lambda)<\frac{1}{c}$. Hence, by applying a similar reasoning, we shall get $\lim _{n \rightarrow+\infty} \beta_{0}^{*}(n, c, \lambda)=\frac{1}{c}$ since $\beta_{r}^{*}(n, c, \lambda) \leq \beta_{0}^{*}(n, c, \lambda)$. The claim $\beta_{0}^{*}(n, c, \lambda)<\frac{1}{c}$ is equivalent to $(n-1) c^{2} \xi^{2}+c(3+c-n) \xi-(1+c)<0$. To see this we distinguish two cases.

- If $n=1$, then the above inequality holds if and only if $\xi<\frac{1+c}{2 c+c^{2}}$, and this is equivalent to say that $P_{n, c, \lambda}\left(\frac{1+c}{2 c+c^{2}}\right)>0$, which is true since further computations lead to

$$
P_{n, c, \lambda}\left(\frac{1+c}{2 c+c^{2}}\right)=\frac{1}{c(2+c)^{3}}\left(1+c+\left(c^{2}+3 c+3\right)(1-\lambda)\right)>0 .
$$

- If $n>1$, then the above inequality holds if and only if $\xi<\frac{n-c-3+\sqrt{(n+c-1)^{2}+4(1+c)}}{2 c(n-1)}=$ : $\theta(n, c)$, and this is equivalent to say that $P_{n, c, \lambda}(\theta(n, c))>0$. Again, further computations lead to

$$
P_{n, c, \lambda}(\theta(n, c))=\frac{1}{2 c(n-1)^{3}}(u \lambda+v) \geq \frac{1}{2 c(n-1)^{3}}(u+v)>0
$$

where $u=-4 n c^{2}-6 n c-c-1-2 c^{2} n^{2}-c n^{3}-n c^{3}+n^{2}-4 c n^{2}-2 n^{3}-6 n+\left(2 n^{2}+\right.$ $\left.n+1+c n^{2}+n c^{2}+3 n c\right) \sqrt{w}, v=-1-2 n c+n^{3}-n^{2}-n+c n^{2}+c+\left(2 n-n^{2}-1\right) \sqrt{w}$ and $w=(n+c-1)^{2}+4(1+c)$. The first two inequalities in (10) follow from the fact that $\lambda \in[0,1], u \leq 0$ and $u+v \geq 0$ since

$$
\begin{aligned}
\sup \{u: n \in \mathbb{N}, c \geq 0\} & =0, \\
\inf \{u+v: n \in \mathbb{N}, c \geq 0\} & =0,
\end{aligned}
$$

again by using the software BARON.

Proof of Proposition 4 .

(i) Let $\xi=\beta_{r}^{*}(n, c, \lambda)$. In order to compute $\frac{\partial \xi}{\partial c}$, we use that $P_{n, c, \lambda}(\xi)=0$ and employ implicit differentiation. Consequently, we get

$$
\frac{\partial \xi}{\partial c}=-\frac{H_{n, c, \lambda}(\xi)}{P_{n, c, \lambda}^{\prime}(\xi)}
$$


where $H_{n, c, \lambda}(x):=b_{3} x^{3}+b_{2} x^{2}+b_{1} x+b_{0}$ with $b_{i}=\frac{\partial a_{i}}{\partial c}$ for $i=0,1,2,3$, that is,

$$
\begin{aligned}
& b_{3}=2 n c(n-1+\lambda), \\
& b_{2}=-n^{2}+(4 c+4-3 \lambda) n-2 c-1+\lambda, \\
& b_{1}=-2 n+2 c+4-\lambda, \\
& b_{0}=-1 .
\end{aligned}
$$

We know that $P_{n, c, \lambda}^{\prime}(\xi)>0$ (see the proof of Theorem 1). So next, we prove $H_{n, c, \lambda}(\xi) \geq 0$ which ensures $\frac{\partial \xi}{\partial c} \leq 0$. Observe that $H_{n, c, \lambda}(0)=b_{0}<0$ and $\lim _{x \rightarrow+\infty} H_{n, c, \lambda}(x)=+\infty$ (since $b_{3}>0$, except for $n=1$ and $\lambda=0$, in which case $b_{3}=0$ and $\left.b_{2}=2 c+2>0\right)$. Now, we claim that $H_{n, c, \lambda}(\vartheta(n, c)) \geq 0$. Further computations lead to

$$
H_{n, c, \lambda}(\vartheta(n, c))=\frac{1}{2 c^{2} n^{2}}(u \lambda+v) \geq \frac{1}{2 c^{2} n^{2}}(u+v) \geq 0
$$

where $u=\left(n c-5 c^{2}-1+n^{2}-n^{3}-2 c^{3}+n-2 n c^{2}-4 c-c n^{2}\right)+\left(-n^{2}+3 c+2 c^{2}+1\right) \sqrt{w}$, $v=\left(1+c^{2} n^{2}+2 c+n^{4}-2 n^{3}+2 n^{3} c+2 n^{2}+c^{2}-2 n\right)+\left(n-1+n^{3}-n^{2}+c n^{2}-c\right) \sqrt{w}$ and $w=(n+c-1)^{2}+4 c$. The two inequalities in (11) follow from the fact that $\lambda \in[0,1], u \leq 0$ and $u+v \geq 0$ since

$$
\begin{aligned}
\sup \{u: n \in \mathbb{N}, c \geq 0\} & =0, \\
\inf \{u+v: n \in \mathbb{N}, c \geq 0\} & =0,
\end{aligned}
$$

again by using the software BARON. Now, we study the monotonicity of the polynomial $H_{n, c, \lambda}(x)$ in $\mathbb{R}_{+}$. We have $H_{n, c, \lambda}^{\prime}(0)=b_{1}$ and $H_{n, c, \lambda}^{\prime}(x)=0$ if and only if $x=\frac{-b_{2} \pm \sqrt{\Delta}}{3 b_{3}}$ where $\Delta:=b_{2}^{2}-3 b_{1} b_{3}$. We discuss the following cases:

- If $b_{1}<0$, then $\Delta>b_{2}^{2} \geq 0$ and $H_{n, c, \lambda}$ has two stationary points with different sign, say $\underline{z}<0$ and $\bar{z}>0$. This means that $H_{n, c, \lambda}$ is strictly decreasing in $(0, \bar{z})$ and strictly increasing in $(\bar{z},+\infty)$. Consequently, $H_{n, c, \lambda}(\bar{z})<H_{n, c, \lambda}(0)<0$ and so, in virtue of (11), one gets $\bar{z}<\vartheta(n, c) \leq \xi$. Thus, $H_{n, c, \lambda}(\xi) \geq H_{n, c, \lambda}(\vartheta(n, c)) \geq 0$.

- If $b_{1} \geq 0$ and $\Delta<0$, then $H_{n, c, \lambda}$ has no stationary points and it is strictly increasing in $\mathbb{R}$, which shows that $H_{n, c, \lambda}(\xi) \geq H_{n, c, \lambda}(\vartheta(n, c)) \geq 0$.

- If $b_{1} \geq 0$ and $\Delta \geq 0$, then we get $b_{2} \geq 0$. This follows from the fact that

$$
\inf \left\{b_{2}: b_{1} \geq 0, \Delta \geq 0, n \in \mathbb{N}, c \geq 0, \lambda \in[0,1]\right\}=0,
$$

obtained by using the software BARON. Hence, in this case, $H_{n, c, \lambda}$ has (at most two) stationary points which are lower or equal than 0 , and so it is strictly increasing in $(0,+\infty)$, which shows again that $H_{n, c, \lambda}(\xi) \geq H_{n, c, \lambda}(\vartheta(n, c)) \geq 0$.

Next we show that $\frac{\partial \beta_{0}^{*}(n, c, \lambda)}{\partial c} \leq \frac{\partial \beta_{r}^{*}(n, c, \lambda)}{\partial c}$. By differentiation,

$$
\frac{\partial\left(\beta_{0}^{*}-\beta_{r}^{*}\right)}{\partial c}=\frac{\partial\left(\beta_{0}^{*}-\beta_{r}^{*}\right)}{\partial \xi} \cdot \frac{\partial \xi}{\partial c}=\frac{-n c^{2} \xi^{2}+2 n c \xi+1-n}{(1-c \xi)^{2}} \cdot \frac{\partial \xi}{\partial c} \leq 0
$$

since $\frac{\partial \xi}{\partial c} \leq 0$ and $-n c^{2} \xi^{2}+2 n c \xi+1-n>0$ (see the proof of Proposition 2)).

(ii) and (iii) can be derived from Propositions 1 and 3. Since $\vartheta(n, c) \leq \beta_{r}^{*}(n, c, \lambda) \leq$ $\beta_{0}^{*}(n, c, \lambda)<\frac{1}{c}$, the conclusion follows by taking limits. 
Proof of Proposition 5.

It follows from Propositions 1 and 2 , since $\frac{\partial \xi}{\partial \lambda}>0$ and $1-c \xi>0$. Thus,

$$
\begin{gathered}
\frac{\partial p^{*}}{\partial \lambda}=\frac{\partial}{\partial \lambda}\left((\alpha+\varepsilon) \cdot \frac{1-c \xi}{\xi(2-c \xi)}\right)=(\alpha+\varepsilon) \cdot \frac{-c^{2} \xi^{2}-2(1-c \xi)}{[\xi(2-c \xi)]^{2}} \cdot \frac{\partial \xi}{\partial \lambda}<0, \\
\frac{\partial q_{r}^{*}}{\partial \lambda}=\frac{\partial}{\partial \lambda}\left((\alpha+\varepsilon) \cdot \frac{1-c \xi}{2-c \xi}\right)=(\alpha+\varepsilon) \cdot \frac{-c}{[\xi(2-c \xi)]^{2}} \cdot \frac{\partial \xi}{\partial \lambda}<0, \text { and } \\
\frac{\partial q_{0}^{*}}{\partial \lambda}=\frac{\partial}{\partial \lambda}\left((\alpha+\varepsilon) \cdot \frac{(n-1) c \xi^{2}+(2+c-n) \xi-1}{\xi(2-c \xi)}\right)=(\alpha+\varepsilon) \cdot \frac{\left(c^{2}+n c\right) \xi^{2}+2(1-c \xi)}{[\xi(2-c \xi)]^{2}} \cdot \frac{\partial \xi}{\partial \lambda}>0 .
\end{gathered}
$$

Proof of Proposition 6.

Observe that

$$
\pi_{r}^{*}-\pi_{0}^{*}=(\alpha+\varepsilon)^{2} \cdot \frac{w_{4} \xi^{4}+w_{3} \xi^{3}+w_{2} \xi^{2}+w_{1} \xi+w_{0}}{2 \xi^{2}(2-c \xi)^{2}}
$$

where $w_{4}=c^{3}\left(n^{2}-2 n\right), w_{3}=2 c^{3}(n-1)-2 c^{2}\left(n^{2}-4 n+1\right), w_{2}=c^{3}+c^{2}(8-4 n)+c\left(n^{2}-8 n+5\right)$, $w_{1}=-2 c^{2}+2 c(n-4)+2(n-1)$ and $w_{0}=2+c$. Letting $W_{n, c}(x)=w_{4} x^{4}+w_{3} x^{3}+w_{2} x^{2}+$ $w_{1} x+w_{0}$, we just need to show $W_{n, c}(\xi) \leq 0$ so as to conclude $\pi_{r}^{*} \leq \pi_{0}^{*}$. For that purpose, we distinguish three cases.

- If $n=1$, then $w_{4}=-c^{3}<0$ and so $\lim _{x \rightarrow \pm \infty} W_{1, c}(x)=-\infty$. The degree 4 polynomial $W_{1, c}(x)$ has four real roots: $\kappa_{1,2}:=\frac{-c \pm \sqrt{c^{2}+4 c}}{2 c}$ and $\kappa_{3,4}:=\frac{4+c \pm \sqrt{c^{2}+4 c+8}}{2 c}$. It can be shown that $\kappa_{2}<\kappa_{1}<\kappa_{4}<\kappa_{3}$. Now, we claim $\kappa_{1} \leq \gamma \leq \kappa_{4}$, which implies $W_{1, c}(\xi) \leq 0$. The inequality $\kappa_{1} \leq \gamma$ has been stated in Theorem 1, whereas the second inequality follows from the monotonicity of $P_{1, c, \lambda}$ and the fact that

$$
P_{1, c, \lambda}\left(\kappa_{4}\right)=\frac{1}{2 c}(u \lambda+v) \geq \frac{1}{2 c}(u+v) \geq 0,
$$

where $u=\left(c^{3}+6 c^{2}+16 c+16\right)-\left(c^{2}+4 c+6\right) \sqrt{w}, v=\left(2 c^{3}+12 c^{2}+28 c+24\right)-\left(2 c^{2}+\right.$ $8 c+8) \sqrt{w}$ and $w=c^{2}+4 c+8$. The first inequality in (12) follows because $u \leq 0$, and the second one because $u+v \geq 0$. Thus, the conclusion follows.

- If $n=2$, then $w_{4}=0, w_{3}=2 c^{3}+6 c^{2}>0$ and so $\lim _{x \rightarrow \pm \infty} W_{2, c}(x)= \pm \infty$, respectively. The degree 3 polynomial $W_{2, c}(x)$ has three real roots: $\kappa_{1,2}=\frac{1-c \pm \sqrt{c^{2}+6 c+1}}{4 c}$ and $\kappa_{3}=$ $\frac{c+2}{c(c+3)}$. It can be shown that $\kappa_{2}<\kappa_{1}<\kappa_{3}$. Now, we claim $\kappa_{1} \leq \gamma \leq \kappa_{3}$, which implies $W_{2, c}(\xi) \leq 0$. We just need to show $\gamma \leq \kappa_{3}$, which follows as a consequence of the monotonicity of $P_{2, c, \lambda}$ and the fact that

$$
P_{2, c, \lambda}\left(\kappa_{3}\right)=\frac{2 c^{2}+12 c+16-\lambda\left(c^{2}+5 c+8\right)}{c(c+3)^{2}} \geq 0 .
$$

- If $n>2$, then $w_{4}>0$ and so $\lim _{x \rightarrow \pm \infty} W_{n, c}(x)=+\infty$. The degree 4 polynomial $W_{n, c}(x)$ has four real roots: $\kappa_{1,2}:=\frac{(n-c-1) \pm \sqrt{(n-c-1)^{2}+4 n c}}{2 n c}$ and $\kappa_{3,4}:=\frac{(n-c-5) \pm \sqrt{(n-c-1)^{2}+4 n c+8}}{2(n-2) c}$. 
It can be shown that $\kappa_{4}<\kappa_{2}<\kappa_{1}<\kappa_{3}$. Now, we claim $\kappa_{1} \leq \gamma \leq \kappa_{3}$, which implies $W_{n, c}(\xi) \leq 0$. The inequality $\kappa_{1} \leq \gamma$ has been stated in Theorem 1 , whereas the second inequality follows from the monotonicity of $P_{n, c, \lambda}$ and the fact that

$$
P_{n, c, \lambda}\left(\kappa_{3}\right)=\frac{1}{2 c(n-2)^{3}}(u \lambda+v) \geq \frac{1}{2 c(n-2)^{3}}(u+v) \geq 0,
$$

where $u=\left(-6 n c^{2}+4 n^{2}-2 c^{2} n^{2}-n c^{3}-c n^{3}-4 n^{3}+6-22 n-7 c n-8 c n^{2}+2 c^{2}\right)+$ $\left(5 c n+n c^{2}+2+c n^{2}-2 c+4 n^{2}\right) \sqrt{w}, v=\left(-6-10 c-12 n-6 n c^{2}-4 c n^{2}-14 c n-6 c^{2}-\right.$ $\left.2 c^{3}-6 n^{2}\right)+\left(10 n+4 c+2 c^{2}-2+4 n c\right) \sqrt{w}$ and $w=9-2 n+2 c+n^{2}+2 c n+c^{2}$. The two inequalities in (13) follow from the fact that $\lambda \in[0,1], u \leq 0$ and $u+v \geq 0$ since

$$
\begin{array}{r}
\sup \{u: n \in \mathbb{N}, n \geq 3, c \geq 0\}=0, \\
\inf \{u+v: n \in \mathbb{N}, n \geq 3, c \geq 0\}=0,
\end{array}
$$

again by using the software BARON. Thus, the conclusion follows.

Next, we prove $\frac{\partial \pi_{0}^{*}}{\partial \lambda}<0$. Since $\pi_{0}^{*}=p^{*} q_{0}^{*}-\frac{c}{2}\left(q_{0}^{*}\right)^{2}=(\alpha+\varepsilon)^{2} \cdot \frac{\beta_{0}^{*}-\frac{c}{2}\left(\beta_{0}^{*}\right)^{2}}{\left(1+\beta_{0}^{*}+n \beta_{r}^{*}\right)^{2}}$, then

$$
\frac{\partial \pi_{0}^{*}}{\partial \lambda}=\frac{\partial \pi_{0}^{*}}{\partial \beta_{r}^{*}} \cdot \frac{\partial \beta_{r}^{*}}{\partial \lambda}+\frac{\partial \pi_{0}^{*}}{\partial \beta_{0}^{*}} \cdot \frac{\partial \beta_{0}^{*}}{\partial \lambda} .
$$

By Proposition 2 we know that $\frac{\partial \beta_{0}^{*}}{\partial \lambda}>0$ and $\frac{\partial \beta_{r}^{*}}{\partial \lambda}>0$. Now, we observe that

$$
\begin{aligned}
& \frac{\partial \pi_{0}^{*}}{\partial \beta_{r}^{*}}=(\alpha+\varepsilon)^{2} \cdot \frac{-n \beta_{0}^{*}\left(2-c \beta_{0}^{*}\right)}{\left(1+\beta_{0}^{*}+n \beta_{r}^{*}\right)^{3}}<0, \\
& \frac{\partial \pi_{0}^{*}}{\partial \beta_{0}^{*}}=(\alpha+\varepsilon)^{2} \cdot \frac{\left(1+n \beta_{r}^{*}\right)\left(1-c \beta_{0}^{*}\right)-\beta_{0}^{*}}{\left(1+\beta_{0}^{*}+n \beta_{r}^{*}\right)^{3}} \leq 0,
\end{aligned}
$$

which ensures that $\frac{\partial \pi_{0}^{*}}{\partial \lambda}<0$, since $1-c \beta_{0}^{*}>0$ (see the proof of Proposition 3 ) and

$$
\left(1+n \beta_{r}^{*}\right)\left(1-c \beta_{0}^{*}\right) \leq\left(1+n \beta_{r}^{*}\right)\left(1-c \beta_{r}^{*}\right) \leq \beta_{r}^{*} \leq \beta_{0}^{*},
$$

which follow from the fact that $\vartheta(n, c) \leq \beta_{r}^{*} \leq \beta_{0}^{*}$ (see Propositions 1 and 3 ).

Now we show

$$
\frac{\partial \pi_{r}^{*}}{\partial \lambda}=\frac{\partial}{\partial \lambda}\left((\alpha+\varepsilon)^{2} \cdot \frac{(1-c \xi)^{2}}{2 \xi(2-c \xi)}\right)=(\alpha+\varepsilon)^{2} \cdot \frac{-(1-c \xi)}{[\xi(2-c \xi)]^{2}} \cdot \frac{\partial \xi}{\partial \lambda}<0 .
$$

We next prove $\frac{\partial C S^{*}}{\partial \lambda}>0$. Since $C S^{*}=(\alpha+\varepsilon)^{2} \cdot \frac{\left(\beta_{0}^{*}+n \beta_{r}^{*}\right)^{2}}{2\left(1+\beta_{0}^{*}+n \beta_{r}^{*}\right)^{2}}$, then

$$
\frac{\partial C S^{*}}{\partial \lambda}=\frac{\partial C S^{*}}{\partial \beta_{r}^{*}} \cdot \frac{\partial \beta_{r}^{*}}{\partial \lambda}+\frac{\partial C S^{*}}{\partial \beta_{0}^{*}} \cdot \frac{\partial \beta_{0}^{*}}{\partial \lambda} .
$$

By Proposition 2 we know that $\frac{\partial \beta_{0}^{*}}{\partial \lambda}>0$ and $\frac{\partial \beta_{r}^{*}}{\partial \lambda}>0$. Now, we observe that

$$
\frac{\partial C S^{*}}{\partial \beta_{r}^{*}}=(\alpha+\varepsilon)^{2} \cdot \frac{n\left(\beta_{0}^{*}+n \beta_{r}^{*}\right)}{\left(1+\beta_{0}^{*}+n \beta_{r}^{*}\right)^{3}}>0 \quad \text { and } \quad \frac{\partial C S^{*}}{\partial \beta_{0}^{*}}=(\alpha+\varepsilon)^{2} \cdot \frac{\beta_{0}^{*}+n \beta_{r}^{*}}{\left(1+\beta_{0}^{*}+n \beta_{r}^{*}\right)^{3}}>0
$$


which ensures $\frac{\partial C S^{*}}{\partial \lambda}>0$.

Finally, we show $\frac{\partial S W^{*}}{\partial \lambda}>0$. Since $S W^{*}=(\alpha+\varepsilon)^{2} \cdot \frac{\left(\beta_{0}^{*}+n \beta_{r}^{*}\right)^{2}+2\left(\beta_{0}^{*}+n \beta_{r}^{*}\right)-c\left(\left(\beta_{0}^{*}\right)^{2}+n\left(\beta_{r}^{*}\right)^{2}\right)}{2\left(1+\beta_{0}^{*}+n \beta_{r}^{*}\right)^{2}}$, then

$$
\frac{\partial S W^{*}}{\partial \lambda}=\frac{\partial S W^{*}}{\partial \beta_{r}^{*}} \cdot \frac{\partial \beta_{r}^{*}}{\partial \lambda}+\frac{\partial S W^{*}}{\partial \beta_{0}^{*}} \cdot \frac{\partial \beta_{0}^{*}}{\partial \lambda} .
$$

By Proposition 2 we know that $\frac{\partial \beta_{0}^{*}}{\partial \lambda}>0$ and $\frac{\partial \beta_{r}^{*}}{\partial \lambda}>0$. Now, we observe that

$$
\begin{aligned}
\frac{\partial S W^{*}}{\partial \beta_{r}^{*}} & =(\alpha+\varepsilon)^{2} \cdot \frac{n\left(\left(1-c \beta_{r}^{*}\right)+c \beta_{0}^{*}\left(\beta_{0}^{*}-\beta_{r}^{*}\right)\right)}{\left(1+\beta_{0}^{*}+n \beta_{r}^{*}\right)^{3}}>0, \\
\frac{\partial S W^{*}}{\partial \beta_{0}^{*}} & =(\alpha+\varepsilon)^{2} \cdot \frac{1-c \beta_{0}^{*}-n c \beta_{0}^{*} \beta_{r}^{*}+n c\left(\beta_{r}^{*}\right)^{2}}{\left(1+\beta_{0}^{*}+n \beta_{r}^{*}\right)^{3}} \geq 0,
\end{aligned}
$$

which ensures $\frac{\partial S W^{*}}{\partial \lambda}>0$. We just need to show that $1-c \beta_{0}^{*}-n c \beta_{0}^{*} \beta_{r}^{*}+n c\left(\beta_{r}^{*}\right)^{2} \geq 0$. This inequality is equivalent to

$$
\beta_{0}^{*}+n \beta_{r}^{*}\left(\beta_{0}^{*}-\beta_{r}^{*}\right) \leq \frac{1}{c} .
$$

Since $\beta_{0}^{*}$ and $\beta_{r}^{*}$ are functions of the privatization parameter $\lambda$, we define $\ell(\lambda):=\beta_{0}^{*}+$ $n \beta_{r}^{*}\left(\beta_{0}^{*}-\beta_{r}^{*}\right)$. Now, we see that $\ell$ is an increasing function of $\lambda$. For that purpose, we write $\ell(\lambda)=\beta_{0}^{*}+n \beta_{r}^{*} \beta_{t}^{*}$ by introducing $\beta_{t}^{*}:=\beta_{0}^{*}-\beta_{r}^{*} \geq 0$. Thus,

$$
\frac{d \ell}{d \lambda}=\frac{\partial \ell}{\partial \beta_{0}^{*}} \cdot \frac{\partial \beta_{0}^{*}}{\partial \lambda}+\frac{\partial \ell}{\partial \beta_{r}^{*}} \cdot \frac{\partial \beta_{r}^{*}}{\partial \lambda}+\frac{\partial \ell}{\partial \beta_{t}^{*}} \cdot \frac{\partial \beta_{t}^{*}}{\partial \lambda}=\frac{\partial \beta_{0}^{*}}{\partial \lambda}+n \beta_{t}^{*} \cdot \frac{\partial \beta_{r}^{*}}{\partial \lambda}+n \beta_{r}^{*} \cdot \frac{\partial \beta_{t}^{*}}{\partial \lambda} \geq 0
$$

in virtue of Proposition 2. Thus, $\ell^{\prime}(\lambda) \geq 0$ and so $\ell(\lambda) \leq \ell(1)=\beta_{0}^{*}(1)+n \beta_{r}^{*}(1)\left(\beta_{0}^{*}(1)-\beta_{r}^{*}(1)\right)$ for all $\lambda \in[0,1]$. By letting $\widetilde{\xi}=\beta_{r}^{*}(1)$, then in virtue of (8) we get

$$
\beta_{0}^{*}(1)=\frac{1+n c \widetilde{\xi}^{2}}{c(1+n \widetilde{\xi})}
$$

and so $\ell(\lambda) \leq \ell(1)=\frac{1}{c}$. Thus, (14) is proved and the proof of the proposition concludes. 


\section{Notes}

1. Indeed, there can be two extreme cases: the policy-maker may privatize a monopolistic state-owned firm without opening-up the market to competitors (privatization without liberalization), or opening-up the market retaining the full ownership of the public firm (liberalization without privatization).

2. Indeed, in most of the bidding systems, generators submit day-ahead offers on an hourly basis according to the future demand forecast.

3. Other approaches use Cournot models to describe some features of the electricity generation market. See for instance Borenstein and Bushnell (1999) for California's case.

4. Admittedly, our results depend on the competition mode assumed, namely, the supply function competition. However, they are also in line with the results mentioned above in a homogeneous or differentiated oligopoly with an exogenous number of firms suggesting that privatization is more likely to be beneficial when the market is more competitive.

5. For instance, Wolfram (1999) presents an empirical study of market power in the British electricity industry or Borenstein and Bushnell (1999) analyze how the wave of liberalization and restructuring in the US electricity market has modified the incentives to exert horizontal market power.

6. A model of supply function competition with a Stackelberg leader can be found in Delbono and Lambertini (2018).

7. A deep explanation about this point can be found in Klemperer and Meyer (1989).

8. As stated in De Fraja and Delbono (1990), if each firm's marginal cost is constant the public firm will impose the rule of pricing at marginal cost. This is true independently of the relative efficiency of private and public firms. We abstract from this issue by considering increasing marginal costs, as it is the case in electric power generation.

9. It is possible to specify a more general setting where supply functions are defined as $q_{i}=v_{i}+\beta_{i} p_{i}$. However, when the marginal cost has a zero intercept, a supply function equilibrium of the form $q_{i}=\beta_{i} p_{i}$ exists (see Klemperer and Meyer (1989)). For the sake of simplicity and without loss of generality, and following Ciarreta and Gutiérrez-Hita (2006, 2012) and Delbono and Lambertini (2015), we take $v_{i}=0$.

10. In a very recent paper, Futagami et al. (2019) also show that an increase in the degree of privatization increases the market price in a wide range of parameter spaces when a Markov-perfect Nash equilibrium is considered.

11. We thank a referee for suggesting this approach.

12. The optimal value of the above mixed-integer non-linear programming (MINLP) problem has been obtained by using the MATLAB/BARON interface of the software BARON developed by N. V. Sahinidis's research group (see Sahinidis et al. (2018), and Kronqvist et al. (2019) for a review on MINLP solvers). 